\title{
The Mid-term Evaluation Method for the “Twelfth Five-year" Planning of Shanxi Road and Waterway Based on Mid-term Target Realization Degree
}

\author{
Hu Tiejun, Liu Xin, Liu Yin, Wang Xianguang \\ Transportation Technical Advisory Center \\ China Academy of Transportation Sciences
}

No. 240 of Huixinli, Chaoyang District, Beijing-China, 100029

\begin{abstract}
This paper proposes a comprehensive method, named realization degree mid-term evaluation,to assess indicators during "Twelfth Five-year" mid-term. Meanwhile it establishes mid-term evaluation for the "Twelfth Five-year" planning of Shanxi indicator system constituted by three hierarchies,such as target, criterion, indicator and mid-term evaluation method and procedures. According to scores of different indicators, four progress statuses and other criteria, it proposed conclusion about mid-term evaluation of indicators. Moreover, indicators achieved in advance would be rectified based on practical effect.
\end{abstract}

Keywords-Mid-term evaluation; Realization degree; Five-year planning; Evaluation criterion; Rectification.

\section{INTRODUCTION}

The "Twelfth Five-year plan" for the highway and waterway transport of Shaanxi published in 2011 by Shaanxi Provincial Transport Department presented the development goals in the following five aspects: transport infrastructure, maintaining service, public service, transportation service and sustainable development. At the first 3 years of the "Twelfth Five-year plan", Shanxi transport industry has a smooth development, however, also constantly faces the adjustments due to the changes in the national and provincial situations. The adjustments are urgent in the next 2 years of the "Twelfth Five-year plan" based on the evalution results. Thus, it is an important task to present an effective method for the mid-term evaluation of development in the past 3 years of the "Twelfth Five-year plan", which will be helpful to the following two years.

\section{PROPOSITION OF THE INDICATORS IN MID-TERM TARGET REALIZATION DEGREE}

Mid-term evaluation requires the normalization of all the evaluation indicators with different dimensions, which could finally lead us to the mid-term realization situation of the "Twelfth Five-year" planning. To realize this goal, a unified evaluation method is required to satisfy all different dimensional indicators in the system. According to the papers we reviewed, currently, realization degree evaluation is mostly applied in the realization degree of the overall well-off society construction, the related new rural area construction and modernization. The forms of realization degree basically represent as having specific vision and goal, such as the realization degree of the overall well-off society construction, the related new rural area construction and modernization. While the measurement of realization degree is based on the integrated result of a series of indicators or indicator systems related to the vision and goal. As a sub-system in the national economic system, the "Twelfth Five-year" planning of the transportation system can be, the same as the overall well-off society construction, the related new rural area construction and modernization, represented as a series of indicators. This paper, on the fundamental basis of different evaluation studies, used realization degree as an indicator to conduct a comprehensive mid-term evaluation of the "Twelfth Five-year" traffic planning of Shanxi road and waterway.

\section{EVALUATION METHOD}

\subsection{Evaluation thread and process}

The indicator system of mid-term evaluation of the "Twelfth Five-year" traffic planning is an indicator system with multi-objective and multi-layer. It can be classified into 3 layers: the objective layer, the principle layer and the indicator layer (shown in Table 1). By applying the analytic hierarchy process to the evaluation value of the indicator layer and the principle layer, we can get the integrated evaluation value of the objective layer. For the evaluation value of the indicator layer, it can be categorized into 2 types according to their characteristics: one is the quantitative indicator, which can be normalized to realization degree indicator based on the analysis of the absolute value represents the actual completion, combined with non-dimensionalization method, so as to make all different indicators comparable; the other one is the qualitative indicator, which can be rationally quantified as realization degree indicator with the same dimension as the former quantitative indicator based on the integrated score graded by the evaluation of related operating department and the experts, combined with specific situation of technical parameters, so as to make all different indicators comparable similarly. 
TABLE 1 INDICATOR SYSTEM OF THE MID-TERM EVALUATION OF THE “TWELFTH FIVE-YEAR” TRAFFIC PLANNING OF SHANXI ROAD AND WATERWAY

\begin{tabular}{|c|c|c|}
\hline Objective Layer & Principle Layer & Indicator Layer \\
\hline \multirow{6}{*}{$\begin{array}{l}\text { 1.Transportation } \\
\text { infrastructure } \\
\text { construction } \\
\text { indicators A }\end{array}$} & $\begin{array}{l}\text { Road construction } \\
\text { scale A1 }\end{array}$ & $\begin{array}{c}\text { Road operation mileage realization degree (A11), Road density realization degree (A12), Highway } \\
\text { total mileage realization degree (A13), Number of provincial exits on highway (A14), Arterial } \\
\text { highway (Class } 2 \text { and above) mileage realization degree (A15), Total rural road mileage realization } \\
\text { degree (A16), Common national road (Class } 2 \text { and above) ratio realization degree (A17), Realization } \\
\text { degree of Shanxi highway ratio in national network (A18) }\end{array}$ \\
\hline & $\begin{array}{c}\text { Road network } \\
\text { coordination } \\
\text { degree A2 }\end{array}$ & $\begin{array}{l}\text { Provincial corridor and adjacent provincial technical standard matching rate (A21), Road (Class } 2 \text { and } \\
\text { above) accessibility for county connecting to highway (A22), Road (Class } 3 \text { and above) accessibility } \\
\text { for county connecting to towns (A23) }\end{array}$ \\
\hline & $\begin{array}{l}\text { Road network } \\
\text { accessibility } \\
\text { degree A3 }\end{array}$ & $\begin{array}{c}\text { Accessibility for provincial capital connecting to prefecture-level cities in } 3 \text { hours (A31), } \\
\text { Accessibility for connecting adjacent prefecture-level cities in } 2 \text { hours (A32), Accessibility for } \\
\text { prefecture-level cities connecting to belonging county (cities) in } 1 \text { hour (A33), Accessibility } \\
\text { realization degree for county connected to highway in half an hour (A34), Accessibility for } \\
\text { connecting counties with highway (A35), Accessibility realization degree for Shanxi connecting } \\
\text { adjacent provincial highway (A36) }\end{array}$ \\
\hline & $\begin{array}{l}\text { Rural road } \\
\text { accessible rate A4 }\end{array}$ & $\begin{array}{c}\text { Town accessibility realization degree (A41), Town patency realization degree (A42), Incorporated } \\
\text { villages accessibility realization degree (A43), Incorporated villages patency realization degree } \\
\text { (A44), Accessibility of road (Class } 4 \text { and above) connection for towns (A45), Paved road ratio } \\
\text { realization degree of Administrative villages (A46) }\end{array}$ \\
\hline & $\begin{array}{l}\text { Poverty } \\
\text { alleviation road } \\
\text { construction A5 }\end{array}$ & $\begin{array}{l}\text { Arterial road framework completion degree in the district (A51), Rural road accessibility and patency } \\
\text { level in the district (A52), Passenger and freight transportation service level (A53), Road safety level } \\
\text { and emergency logistic support capability in the district (A54) }\end{array}$ \\
\hline & $\begin{array}{c}\text { Tourist road } \\
\text { construction A6 }\end{array}$ & $\begin{array}{l}\text { Tourist road network completion degree (A61), Road ancillary service facility completion degree } \\
\text { (A62), Road entry and exit standard (3-level and above) for tourist attractions (A63) }\end{array}$ \\
\hline \multirow{4}{*}{$\begin{array}{l}\text { 2. Maintenance and } \\
\text { service indicators B }\end{array}$} & $\begin{array}{l}\text { Maintenance } \\
\text { management } \\
\text { scheme } \\
\text { construction B1 }\end{array}$ & $\begin{array}{c}\text { Road management and maintenance scheme completion degree (B11), Road maintenance funds } \\
\text { completion rate (B12), Innovation capability of management and maintenance (B13), Application } \\
\text { rate of road condition detection technique (B14) }\end{array}$ \\
\hline & $\begin{array}{l}\text { Maintenance } \\
\text { technical level B2 }\end{array}$ & $\begin{array}{c}\text { Maintenance for road technique and performance (B21), Ratio of provincial arterial road achieving } \\
\text { Class } 2 \text { and above (B22), Dangerous and risky node control (B23), Standard realization degree for } \\
\text { traffic signs and lines (B24) }\end{array}$ \\
\hline & $\begin{array}{l}\text { Freight } \\
\text { transportation } \\
\text { overload and } \\
\text { oversize control } \\
\text { B3 }\end{array}$ & $\begin{array}{l}\text { Overload ratio for road freight transportation (B31), Long-term scheme for overload control (B32), } \\
\text { Equipment level for overload control (B33) }\end{array}$ \\
\hline & $\begin{array}{l}\text { Road } \\
\text { administration } \\
\text { service level B4 }\end{array}$ & $\begin{array}{l}\text { Road case discovery rate, investigation rate and closure rate (B44), Equipment level of road } \\
\text { administration (B45), Informationize management level of road administration (B46) }\end{array}$ \\
\hline \multirow{3}{*}{$\begin{array}{l}\text { 3. Public service } \\
\text { indicators C }\end{array}$} & $\begin{array}{l}\text { Public service } \\
\text { improvement C1 }\end{array}$ & $\begin{array}{l}\text { Technical support for transportation service performance (C11), Political management innovation for } \\
\text { road administration (C12), Provincial information platform construction and information publish } \\
\text { system (C13) }\end{array}$ \\
\hline & $\begin{array}{l}\text { Transportation } \\
\text { service facility } \\
\text { and equipment } \\
\text { Integrity C2 } \\
\end{array}$ & $\begin{array}{c}\text { Real-time surveillance rate for highway and arterial road operation (\%) (C21), Road weather } \\
\text { surveillance network and forecasting service system construction condition for national and } \\
\text { provincial arterial road (C22), Service center coverage rate of highway and national arterial road } \\
\text { (C23), Cyber-ETC average coverage rate of highway network (C24) }\end{array}$ \\
\hline & $\begin{array}{l}\text { Safety and } \\
\text { emergency } \\
\text { logistic support } \\
\text { capability C3 } \\
\end{array}$ & $\begin{array}{c}\text { Fatality rate for traffic accident (C31), Emergency rehabilitation team construction (C32), Emergency } \\
\text { logistic support equipment level (C33), Material reserve system construction (C34), Road weather } \\
\text { surveillance network and forecasting service system construction (C35) }\end{array}$ \\
\hline \multirow{5}{*}{$\begin{array}{l}\text { 4. Transportation } \\
\text { service indicators D }\end{array}$} & $\begin{array}{c}\text { Transportation } \\
\text { service station } \\
\text { construction D1 }\end{array}$ & $\begin{array}{l}\text { Promotion degree for national road transportation hub construction (D11), Promotion for town-level } \\
\text { passenger transport station (D12), Promotion for bus stations in incorporated village (D13) }\end{array}$ \\
\hline & $\begin{array}{l}\text { Public transit } \\
\text { system service for } \\
\text { model Transit } \\
\text { Metropolis D2 }\end{array}$ & $\begin{array}{l}500 \text { meter coverage rate of city bus stations (D21), Taxi share rate (D22), Public transit share rate } \\
\text { (D23), Public transit card penetration (D24), Pubic transportation service level (D25) }\end{array}$ \\
\hline & $\begin{array}{l}\text { Road transport } \\
\text { and integration of } \\
\text { urban and rural } \\
\text { passenger } \\
\text { transport D3 }\end{array}$ & $\begin{array}{l}\text { Inter-city passenger transport diversification (D31), Regular bus service rate for rural passenger } \\
\text { transport (D32), Passenger transport service informatization level (D33) }\end{array}$ \\
\hline & $\begin{array}{l}\text { Transportation } \\
\text { organization and } \\
\text { equipment level } \\
\text { D4 }\end{array}$ & $\begin{array}{l}\text { Vehicle-mounted GPS penetration (D41), Number and proportion of new energy buses (D42), } \\
\text { Proportion of senior coach, heavy truck, special truck, cargo-van and etc. (D43), Equipment level of } \\
\text { heavy truck, cargo-van, refrigerated-insulated van, special truck for dangerous goods and oversized } \\
\text { goods, container truck, LNG new energy vehicle and etc. (D44) }\end{array}$ \\
\hline & $\begin{array}{l}\text { Development } \\
\text { level of modern } \\
\text { logistic industry } \\
\text { D5 }\end{array}$ & $\begin{array}{c}\text { Proportion of road transport charges in total logistic cost (\%) (D51), Actual load rate of operational } \\
\text { truck (D52), Provincial united logistic information sharing platform construction (D53), } \\
\text { Transportation organization form (D54) }\end{array}$ \\
\hline \multirow{2}{*}{$\begin{array}{l}\text { 5. Sustainable } \\
\text { development } \\
\text { indicators E }\end{array}$} & Green ecology E1 & $\begin{array}{l}\text { Effect evaluation regime implementation degree (E11), Implementation degree of "Three } \\
\text { contemporary" regime for environment protection (E12), Water and soil conservation planning for } \\
\text { transportation projects (E13), Greening rate in suitable forestland section (highway and arterial road) } \\
\text { (E14), Realization degree of noise standard qualification for road transportation (E15) }\end{array}$ \\
\hline & $\begin{array}{c}\text { Energy } \\
\text { conservation and } \\
\end{array}$ & $\begin{array}{l}\text { Fuel consumption per hundred vehicle kilometer of operational vehicles (E21), Energy consumption } \\
\text { per unit GDP (E22), Fuel consumption per hundred ship kilometer of operational ships (E23), Total }\end{array}$ \\
\hline
\end{tabular}




\begin{tabular}{|l|c|c|}
\hline & $\begin{array}{c}\text { emission } \\
\text { reduction E2 }\end{array}$ & $\begin{array}{c}\text { ship fuel consumption (E24), Input condition of energy conservation and emission reduction funds } \\
\text { (E25) }\end{array}$ \\
\cline { 2 - 3 } & $\begin{array}{c}\text { Resource } \\
\text { conservation E3 }\end{array}$ & $\begin{array}{c}\text { Average occupancy of cultivated land for road construction (E31), Resource cyclic utilization level } \\
\text { (E32), Main construction material cyclic utilization (E33), Bio-safety disposal and comprehensive } \\
\text { utilization of construction waste, production and domestic sewage (E34) }\end{array}$ \\
\cline { 2 - 3 } & Talent echelon E4 & $\begin{array}{c}\text { Party and government leader with college degree or above major in transportation (E41), Proportion } \\
\text { of technical staff major in transportation (E42), Proportion of technical staff with college degree or } \\
\text { above (E43), Proportion of national expert, provincial expert and senior technician (E44) }\end{array}$ \\
\hline
\end{tabular}

Due to the extensive contents of mid-term evaluation indicators, including not only single-content indicators, but also indicators with wide range of investigation and integrated characteristics, considering the practicality when attaining the data, we mainly divided the indicators (in the indicator layer) into one problem or multiple problems based on the implication of indicators, and designed different options for the problems regarding to quantitative and qualitative indicators. Quantitative indicators mostly attain the first-layer data (the absolute value of completion) directly, which can be normalized into realization degree indicators in a way of non-dimensionalization combined with a reasonable standard value. While for qualitative indicators, options should be set into different levels regarding to different problems. For example, regarding to one specific problem, we could design four options for graders to choose: "finish in advance, running smoothly, running relatively slow, and situation changed”, and set corresponding standard values of realization degree combining with expert experiences. According to statistical analysis and weight calculation, a comprehensive grade by all reviewers would be attained. Based on different weight of problems in that specific indicator, the grades can be quantified into a numerical value between 0 and 100, considered as the realization degree of that indicator. While the quantitative indicators will be processed in a non-dimensionalized way.

According to the state-of-the-art of Shanxi transportation development and requirement of tendency change, the development objective of the "Twelfth Five-year" planning should be regarded as the ultimate goal of the last phase of the "Twelfth Five-year" planning and used to calculate the expected goal of 2013, which could be a comparative target of mid-term evaluation. Combining with the previous indicator calculation method and estimate the realization condition of all indicators compared to the mid-term expected objective of the “Twelfth Five-year" planning, by applying the integrated linear weighted indicator method to conduct a comprehensive evaluation, we could finally calculate the mid-term objective realization degree for indicators in objective layer, principle layer and indicator layer respectively. The following figure shows the process of mid-term evaluation method of the "Twelfth Five-year" traffic planning of Shanxi highway and waterway.

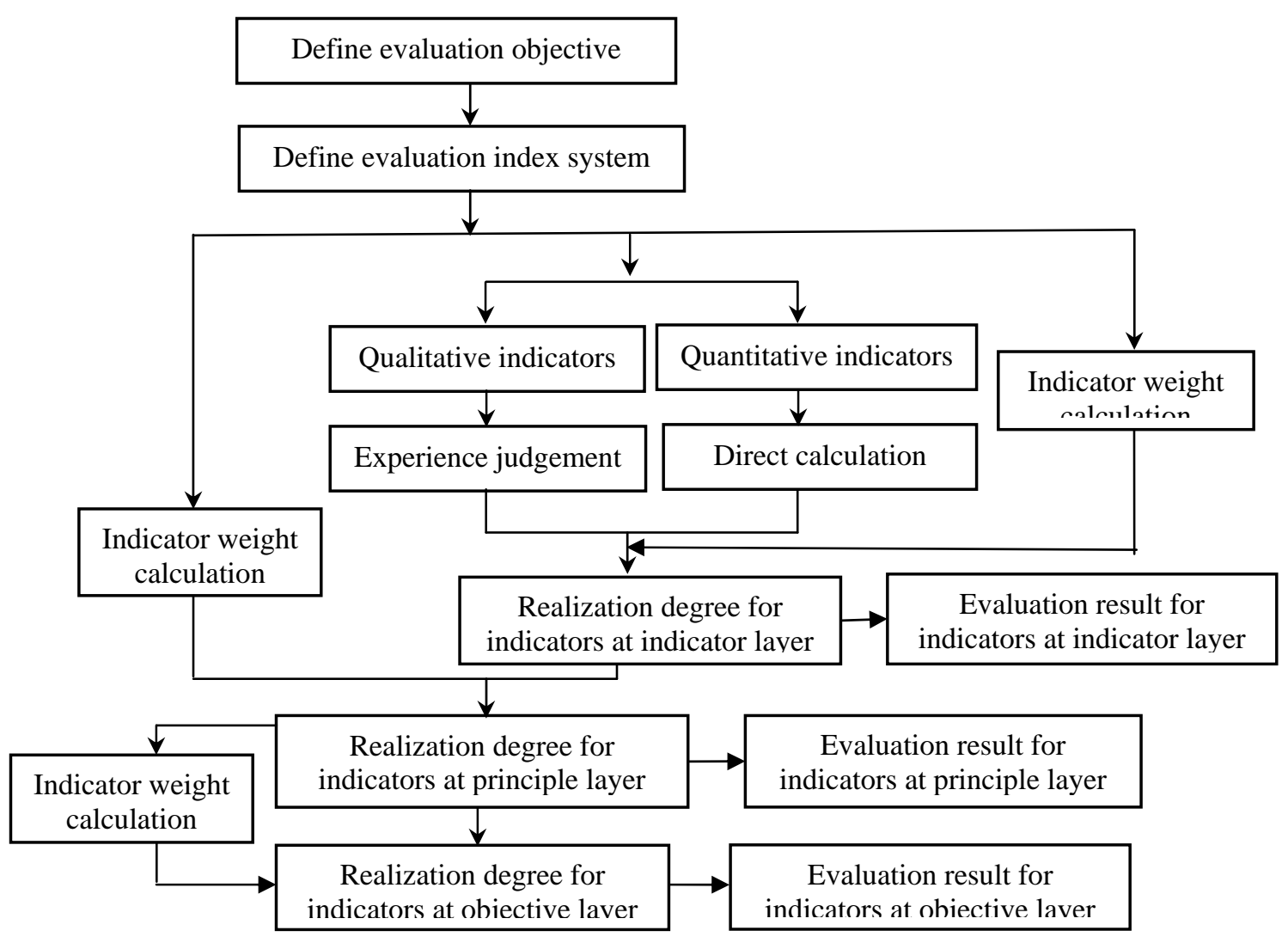

Figure 1. The Mid-term Evaluation Process of the "Twelfth Five-year" Traffic Planning of Shanxi Highway and Waterway 


\subsection{Evaluation criteria of mid-term objective realization degree}

Evaluation should be eventually settled down on the conclusion based on the grades of all indicators. Thus, specific evaluation criteria should be assigned regarding to different development status. The evaluation criteria of the mid-term "Twelfth Five-year" planning can be categorized into 4 statuses: finish in advance, which indicates it can be finished in advance; in good progress, which indicates it can be finished in time; in slow progress, which indicates it needs to be promoted; situation changed, which indicates it is difficult to be finished and the indicators and objectives needs to be adjusted. The four statuses will be specifically explained as follows:

Finish in advance: the realization degree indicator lies in interval [90, 100], which indicates the actual construction has already been completed in the first 2 years of the "Twelfth Five-year". The planning has been playing a significant role in guiding the construction of local transportation system. In addition, the indicators will have positive effects on the future development of Shanxi transportation system.

In good progress: the realization degree indicator lies in interval [80, 90), which indicates there are a few differences between the actual construction status and the planning objective, but most of the projects have been implemented as arranged in the "Twelfth Five-year" planning, which expected to be completed in the "Twelfth Five-year". The planning has been playing a relatively important role in guiding the construction of local transportation system.

In slow progress: the realization degree indicator lies in interval $[70,80)$, which indicates there are many differences between the actual construction status and the planning objective. The planning has some impacts on the construction of local transportation system.

Situation changed: the realization degree indicator lies in interval $[0,70)$, which indicates the projects basically have not been implemented as arranged in the "Twelfth Five-year” planning. The planning has hardly any impacts on the construction of local transportation system. It is necessary to summarize these indicators, or to consider adjusting the objective or indicators based on specific condition.

The corresponding interval of each realization degree in each progress level of the mid-term evaluation of the "Twelfth Five-year" traffic planning of Shanxi highway and waterway can be attained by expert investigation and set-value statistics, as shown in Table 2.

TABLE 2 EVALUATION CRITERIA OF THE INDICATORS

\begin{tabular}{|c|c|c|c|c|}
\hline Evaluation Criteria & Finish in Advance & In Good Progress & In Slow Progress & Situation Changed \\
\hline $\begin{array}{c}\text { Value standard of } \\
\text { realization degree }\end{array}$ & $100 \sim 90$ & $90 \sim 80$ & $80 \sim 70$ & $70 \sim 0$ \\
\hline
\end{tabular}

\subsection{Process of indicators for finish in advance}

Two conditions probably take place regarding indicators for finish in advance: finish in advance with good result and finish in advance with bad result. Different result reflects the differences of the rationality of projects arrangement. Currently, the projects in China are difficult to be expected, leading to construction in advance which usually results in wastage. Therefore, this paper uses a method, based on actual completion, of multiplying a reduction factor $(\xi \in[0.8,1]$ ) to represent the indicators for finish in advance.

\section{CONCLUSION}

Mid-term planning evaluation plays a necessary and significant role in guaranteeing the effective implementation of the projects. It is of great significance to summarize the experiences of planning and implementation timely and to promote the scientific development of transportation industry. During the period of the "Twelfth Five-year", Shanxi transportation industry has been facing both the overall economic social transformation and its own development transformation. Studying the mid-term evaluation method for the "Twelfth Five-year" planning of Shanxi road and waterway, combining with the requirements of the developing environment and tendency change in Shanxi transportation industry during the first 3 years of the "Twelfth Five-year", to establish a mid-term evaluation system for the "Twelfth Five-year” planning and a feedback adjustment mechanism between planning adjustment and planning implementation, thereby timely adjust the emphasis, direction and objective of the "Twelfth Five-year" development can contribute to guarantee the "Twelfth Five-year" planning of Shanxi road and waterway to develop more scientifically and smoothly combining with the tendency change. This paper proposed a mid-term evaluation method for the "Twelfth Five-year" planning of Shanxi road and waterway based on target realization degree combined with the characteristics and requirements of Shanxi transportation mid-term evaluation. By using expert evaluation for qualitative indicators, non-dimensionalization for quantitative indicators and analytic hierarchy process for setting weights to normalize the index system, we could get the evaluation results of the mid-term "Twelfth Five-year" traffic planning of Shanxi road and waterway. According to apply this result to Shanxi traffic planning, certain effects have been well acquired.

\section{REFERENCES}

[1] Ministry of Transport of People's Republic of China. Medium-term Evaluation on Transportation 12th Five-year Planning [R]. 2014.

[2] Fujian Communications Department. Fujian promotes research on transport modernization development [R]. 2014.

[3] Shanxi provincial government. Overall plan for comprehensive reform of economic transition on national resource in Shanxi [R]. 2012.

[4] CHEN Xiao-hong, ZHANG Hua. Objective framework and dynamic paradigm of comprehensive transportation plan evaluation in large cities [J] .Urban Management, 6: 48-51. 
[5] SHI Yuan, Zhou Li-ya. Theory, Method and framework of planning evaluation: a case study of Shenzhen immediate planning [J]. City Planning Review, 2008, 6: 39-43.

[6] LIU Chun-yu, TAN Shuang. Reflection to medium-term Evaluation on outline for national 12th Five-year Planning [J]. China Economic \& Trade Herald, 2008, 11: 26-27.

[7] WANG Zai-jin, Fang Yan, Tian De-lu. The evaluation index system of supporting policies of "National outline for medium and long term S\&T development planning [A]. China Science Forum, 2011, 9:5-10.

[8] YANG Gan-sheng. Evaluation model for government strategic plan based on comprehensive fuzzy estimation [J]. Statistics and Decision, 2008, 11: 46-48.

[9] WU Dian-ting, LI Rui, WU Hao. Evaluation and feedback adjustment on implementation to regional planning__ a case study about national 12th Five-year Planning [J]. Research on Development, 2012, 3:1-5.

[10] WANG Jun, CHEN Xi. About the mechanism of planning evaluation in the western countries: conception, content and evolution of solution [J] . Urban Planning International, 2011, 26 (6): 78-83.

[11] WU Jiang, WANG Xuan-hua. Western planning assessment: evolution of theory and methods for reference [J]. City Planning Review. 2013, 37 (1): 90-96.

[12] YAO Xun, WU Xiu-min. Investigation for realization degree evaluation to new socialist countryside —a case study about Xichong county of Sichuan province[J] . Rural Economy and Science-Technology. 2010, 5: 33-35. 